\title{
Sonographic size of uterus in postmenopausal Sudanese women
}

\author{
MoawiaGamersddin ${ }^{1}$,Maha Haj $\mathrm{Ali}^{2}$, , Mohamed yousef ${ }^{3,4}$ \\ ${ }^{I}$ Taibah University, College of Medical Applied Sciences, Department of Diagnostic Radiologic Technology, \\ Fax: 8475790 P.O: 30001 AlmadinahAlmunawwarah, KSA \\ ${ }^{2}$ Alzaeim Alazhari University, Faculty of Radiological Sciences and Medical Imaging.P.O.Box1432 Khartoum \\ Bahri 13311-Sudan \\ ${ }^{3}$ College of Medical Radiologic Science, Sudan University of Science and Technology.P.O.Box 1908, Khartoum, \\ Sudan \\ ${ }^{4}$ Radiologic technology department, college of applied medical science, Qassim university, Buraduh, KSA .
}

\begin{abstract}
This study aimed to assess the role of sonography in Assessment of uterussize in post-menopausal Sudanese women.Study conducted in different hospitals in Khartoum State and White Nile State to determine the uterine size in postmenopausal Sudanese women from July 2010 to Feb 2011. Atotalof 100 postmenopausal women were selected by non- probability sampling technique and had been scannedwith ultrasound machine using the international protocols.Different uterine measurementshad been taken such as Sagittal uterine length (minimum $4 \mathrm{~cm} /$ maximum $9.3 \mathrm{~cm}$ ), antero-posterior diameter (minimum $1.6 \mathrm{~cm}$ and maximum $4.4 \mathrm{~cm}$ ), transverse diameter (minimum $1.5 \mathrm{~cm}$ and maximum $4.9 \mathrm{~cm}$ ), cervical length (minimum $1.6 \mathrm{~cm}$ and maximum $4.7 \mathrm{~cm}$ ), body to cervix ratio (minimum 1.4 and maximum 3.3) and the uterine volume (minimum $8.35 \mathrm{cc}$ and maximum $94.46 c c)$.All uterine measurements except cervical length were apparently decreased with increasing of age and years since menopause and that is similar to the literature (atrophy uterus occurs mainly in the body of uterus rather than cervix).
\end{abstract}

Key words: Uterine size, postmenopausal, cervix to body ratioSudanese women, ultrasound

\section{Introduction:}

Menopause is defined as a period of women's life which marks the natural permanent cessation of menstrual activity. The occurrence of menopause is different for each women, usually occurs between the age of 40 and 55 years old. The age of when menopause occurs is affected by several factors, including nutrition, malnourished women begin menopause about 4 years earlier thanwell-nourished women, who begin menopause late ${ }^{[1,2]}$ The human uterus is a pear-shaped muscular organ composed of two anatomic region: the cervix and the corpus ${ }^{[3]}$.Non pregnant uterine size varies with age, number of pregnancies and patient endocrinological status, normal adult uterus measures approximately 7.2-9.0 cm long, 4.5-6.0 cm wide and 205-3.5 deep ${ }^{[1,4,5]}$ Menopause is the transition period in a women's life, it occurs when the ovaries stop producing eggs, menstrual activity decreases and eventually ceases, so body decreases the production of female hormones, estrogen and progesterone ${ }^{[6]}$ Menopause effects individual differently. In some cases menstrual activity stops suddenly, but in other menstrual activity tapers off until it completely stops. Menopause is a natural event, occurs between the age of 40-35 post menopausal up to 55 years old. The age of menopause occurs affected by several factors e.g. nutrition, malnourished women begin menopause about 4 years earlier than well-nourished women. The other factor is early onset of menstruation .The main clinical application of ultrasound is to evaluate of post menopausal bleeding and evaluation of palpable pelvic mass. At post menopausal period increase risk for several gynecological diseases including cancer of the breast, ovary and endometrial ${ }^{[7]}$. Previous study showed that there a positive relation between post menopausal hormone use (PMH) and ovarian cancer ${ }^{[8]}$. Other study showed that post menopausal bleeding is an important indicator of the presence of malignancy ${ }^{\text {[9] }}$.Imaging modalities like x-ray radiography, $x$-ray computed tomography [CT] and magnetic resonanceimaging [MRI] have been used in biology and medicine to visualize anatomical structures. ${ }^{[10]}$ Ultrasound is considered the most cost-effective among them. It is used routinely in hospitals and clinics for diagnosing a variety of diseases. It is the tool of choice in obstetrics and cardiology because it is safe and capable of providing imaging in real time. Also Doppler ultrasound is used as a technique for making non-invasive velocity measurements of blood flow. New applications in small-animal imaging and cellular imaging are being explored. ${ }^{[10]}$.Ultrasound machines are better than ever before. To obtain a good image, the operator has to know how to useall of the setting of ultrasound machine and there are many of the concepts that form the basis for adjusting the various settings. Ultrasound machine should be chosenbased on its ability to see a certain structure as well as resolving images and based on its penetrating power. ${ }^{[1]]}$ The endometrium is the lining of the uterus. This lining grows and thickens every month to prepare the uterus for pregnancy. If pregnancy does not occur, the lining is shed during the menstrual period. ${ }^{[12]}$ Endometrial abnormalities are common diagnostic challenges facing the radiologist and referring gynecologist. Ultrasound is the primary imaging modality in this setting. ${ }^{[12]}$ The endometrium 
demonstrates a wide spectrum of normal and pathologic appearance through menarche as well as during prepubertal and postmenopausal years and the first trimester of pregnancy. ${ }^{[13]}$ It is important to understand that the appearance of the endoetrium is related to multiple factors including the patient's age, stage in the menstrual cycle and pregnancy status and whether she has undergone hormonal replacement therapy or tamoxifen therapy. So, these factors should be taken into account in addition to clinical history and physical examination findings. This study aimed to assess the role of sonography in Assessment of uterus size in post-menopausal Sudanese women.

\section{Material and methods:}

Hundred postmenopausal women( whose ages ranged from 41 to 80 years old) were selected by the non- probability sampling technique (from July 2010 to Feb 2011) in different hospitals in Khartoum and White Nile State in Sudan. Different uterine measurements had been taken from the real ultrasound images.

\section{Result and discussion:}

Form the practical point of view it has been found that trans abdominal assessment of uterine size in postmenopausal Sudanese. Hundred women were included in the study by the non probability technique, their ages were ranging from 41 to 80 years and $98 \%$ of them were multiparous ladies. Trans abdominal sonographic examination through full bladder to visualize the uterus, different uterine measurement were taken and found that: mean sagittal uterine length $8 \pm 1.08 \mathrm{~cm}$, mean antero-posterior diameter $2.7 \pm 0.55 \mathrm{~cm}$, mean transverse diameter $3.13 \pm 0.63 \mathrm{~cm}$, mean cervical length $3.01 \pm 0.56$, mean body to cervix ratio $2.13 \pm 0.39$ and mean uterine volume $30.2 \pm 14.97 \mathrm{cc}$.

Table (1) shows that (age group distribution) and table2 shows menopausal groups distribution. The sample included different age groups in different periods following menopause, that aid in the accuracy of the study as well as generalization of the results.

Table (1): Age distribution:

\begin{tabular}{|l|l|}
\hline Age & Percent \\
\hline $41-50$ & $43.0 \%$ \\
\hline $51-60$ & $30.0 \%$ \\
\hline $61-70$ & $22.0 \%$ \\
\hline $71-80$ & $5.0 \%$ \\
\hline Total & $100 \%$ \\
\hline
\end{tabular}

Table (2): Years after menopause distribution:

\begin{tabular}{|l|l|}
\hline Group & Percent \\
\hline$>5$ & $37.0 \%$ \\
\hline $5-10$ & $23.0 \%$ \\
\hline$>10$ & $40.0 \%$ \\
\hline Total & $100 \%$ \\
\hline
\end{tabular}

Figure (1) Showed parity frequency distribution, there was $1 \%$ nulliparous women, $1 \%$ primiparous women and $98 \%$ multiparous women.

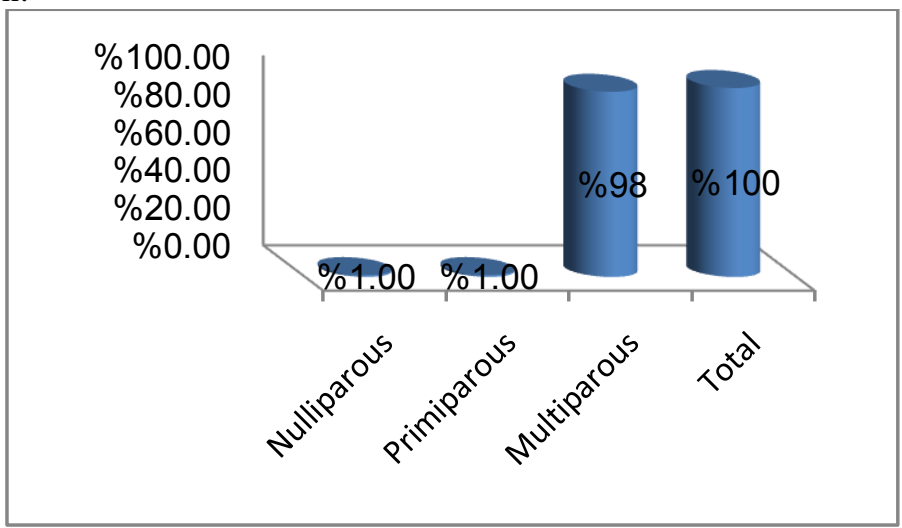

Figure (1) Parity distribution

Table (3) Showed the descriptive statistics of sonographic findings (uterine measurement): mean of sagittal diameter $2.76 \pm 0.55 \mathrm{~cm}$, mean of transverse diameter $3.13 \pm 0.63 \mathrm{~cm}$, mean cervical length $3.01 \pm 0.56 \mathrm{~cm}$, mean of body to cervix ratio $2.13 \pm 0.39$ and mean uterine volume $30.2 \pm 14.97 \mathrm{cc}$ and is correlated with that found by Dr. Gerard M. Dileo (normal uterus is about $7 \mathrm{~cm}$ long and $4 \mathrm{~cm}$ wide and thick). 
Table (3) Sonographic uterine measurement:

\begin{tabular}{|l|l|l|l|l|}
\hline Measures & Mean & Std deviation & Minimum & Maximum \\
\hline Sagittal uterine length & 6.2986 & 1.08149 & 4.00 & 9.30 \\
\hline Antero-posterior diameter & 2.7629 & 0.55 & 1.60 & 4.40 \\
\hline Transverse diameter & 3.136 & 0.63 & 1.5 & 4.9 \\
\hline Cervical length & 3.010 & 0.56 & 1.6 & 4.7 \\
\hline Body to cervix ratio & 2.13 & 0.39 & 1.40 & 3.32 \\
\hline Uterine volume & 30.1898 & 14.97 & 8.35 & 92.46 \\
\hline
\end{tabular}

Table (4, and5) shows that the relationship between age groups and different uterine measurements, including: sagittal antero-posterior and transverse diameter, body to cervix ratio and uterine volume, which decreased with increasing age (except the cervical length which is not significant affected).

Table (4): Relation between age group and body to cervix ratio:

\begin{tabular}{|l|l|l|l|}
\hline Group & Mean & Std deviation & P. value \\
\hline $41-50$ & 2.29 & 0.34 & 0.00 \\
\hline $51-60$ & 2.15 & 0.44 & \\
\hline $61-70$ & 1.87 & 0.22 & \\
\hline $71-80$ & 1.77 & 0.29 & \\
\hline
\end{tabular}

Table (5): Different between age group in uterine volume (cc):

\begin{tabular}{|l|l|l|l|}
\hline Group & Mean & Std deviation & P. value \\
\hline $41-50$ & 39.89 & 15.22 & 0.000 \\
\hline $51-60$ & 25.61 & 10.34 & \\
\hline $61-70$ & 20.58 & 8.86 & \\
\hline $71-80$ & 16.57 & 4.29 & \\
\hline
\end{tabular}

Table (6, and 7) show the effect of years after menopause in different uterine measurements, including: cervical length, body to cervix ratio, and uterine volume, study found that there is a significant reduction in all uterine measurements except the cervical length which is not significant affected.

Table (6): Relation between years after menopausal and body to cervix ratio:

\begin{tabular}{|l|l|l|l|}
\hline Group & Mean & Std deviation & P. value \\
\hline$<5$ & 2.29 & 0.37 & 0.000 \\
\hline $10-5$ & 2.28 & 0.43 & \\
\hline$>10$ & 1.90 & 0.26 & \\
\hline
\end{tabular}

Table (7): Relation between years after menopausal and uterine volume:

\begin{tabular}{|l|l|l|l|}
\hline Group & Mean & Std deviation & P. value \\
\hline$<5$ & 39.41 & 16.04 & 0.00 \\
\hline $10-5$ & 27.94 & 12.78 & \\
\hline$>10$ & 22.96 & 10.11 & \\
\hline
\end{tabular}

\section{Conclusion:}

The effect of age and years after menopausal on different uterine measurements, uterine volume and body cervix to ratio is studies, and found that the uterine volume and size, additional to body cervix ratio were decreasing with increasing both age and period since menopause.

\section{References:}

[1]. Dennis Gartton, RTR. RDMS.RDCS.AAIMS.Lahore Pakistan. The Burwin

[2]. http://www.medscape.com. Accessed on 13/11/2010

[3]. http://www.ajoj.org,com accessed on 13/11/2010

[4]. Prof. Dr. Syed Amir Gilani recorded lectures

[5]. http://www.drapplebaum.com Accessed on 25/10/2010

[6]. http://www.mamasheath.com/default.asp.

[7]. Gynecological on obstetric ultrasound Burwin Institute of U/S module 4 / page 56.

[8]. British Journal of cancer (2007) 96, 151-156. Doi: 10-1038 / Sj.bjc.6603527. http://www.bjcancer.com publishedonline19 December 2006

[9]. http://www.bhj.org/journal2005-4703 Bombay hospital journal- original research.

[10]. 10-Shung, K. Kirk [2006] Diagnostic Ultrasound, Imaging and Blood Flow Measurements, Taylor and Francis

[11]. Stone, C. livinage [2007], Ultrasound in Gynaecology 12- http://www.acog.org, accessed on 27.10. 2010

[12]. 13- http:// www.ajronline.org, accessed on 2710.2010 